Revue d'histoire de l'Amérique française

REVUE D.HISTOIRE DE L'AMÉRIQUE FRANÇAISE

\title{
1685. 30e Janvier. Testament de Noble Homme Charles Le Moyne, escuyer, sieur de Longueuil
}

Volume 6, numéro 2, septembre 1952

URI : https://id.erudit.org/iderudit/301522ar

DOI : https://doi.org/10.7202/301522ar

Aller au sommaire du numéro

Éditeur(s)

Institut d'histoire de l'Amérique française

ISSN

0035-2357 (imprimé)

1492-1383 (numérique)

Découvrir la revue

Citer ce document

(1952). 1685. 30e Janvier. Testament de Noble Homme Charles Le Moyne, escuyer, sieur de Longueuil. Revue d'histoire de l'Amérique française, 6(2),

274-275. https://doi.org/10.7202/301522ar d'utilisation que vous pouvez consulter en ligne.

https://apropos.erudit.org/fr/usagers/politique-dutilisation/ 


\section{DOCUMENTS INÉDITS}

\section{30€ Janvier. TESTAMENT DE NOBLE HOMME CHARLES LE MOYNE ESCUYER SIEUR DE LONGUEUIL.}

PAR DEVANT Benigne Basset Nottaire Royal et de la Terre Et Seigneurie de L'Isle de Montreal en la Nouvelle france et Tesmoings SoubzSignez fut present, Noble homme Charles Le Moyne Escuyer Sieur de Longueuil, Le pere, Lequel estant destenu [ par la ] Maladie en Sa Maison de ville dud Montreal, rue $\mathbf{S}^{\mathrm{t}}$. paul, Toutesfois Sain d'esprit, memoire et Entendement, ainsy qu'il m'est apparu, et ausd Tesmoings,. par Ses Gestes \& maintien. Touttes fois debile A cause de Sa ditte Maladie, Considerant, qu'il n'est rien plus Certain que La mort, et L'heure d'Icelle Incertaine,. et Craignant d'estre prevenu d'Icelle, Voulant auparavant que partir. de Ce Monde, S'il plait a Dieu le retirer, pendant, que, Sens Memoire et Jugement Sont en luy, apres, qu'il a fait le Venerable Signe de la Sainte Croix, et Recommandé Son ame a Nôtre Seigneur JESUS Christ, a la tres Sainte Vierge Marie Sa Mere, A Monsieur $S^{t}$. Michel Ange et Archange et a Tous les Saints \& Saintes de Paradis, a fait \& dicté, Son Testament \& ordonnance de derniere Volonté ainsy qu'il ensuit, C'EST, a Sçavoir, Que Considerant que par le Contract de Mariage, qu'il a fait \& passé Entre luy et damoiselle Catherine primot Son Espouse, elle N'est douée d'aucun douaire, S'y ce N'est du Coustumier, Suivant la Coustume de paris, qui Ne peut estre que Sur les propres, Et que n'en ayant Aucuns, Il Seroit a trop grand prejudice, aladitte damoiselle Son Espouse, qui se trouve Chargée de treise Enfans, et Singulièrem ${ }^{t}$. de Unze Mineurs dans, [ sie ] dont la plus part en tres bas Aage, VEU Toutes Ses Considerations, Et afin de Donner un plus grand Moyen a laditte damoiselle Son Espouse, d'Eslever, et Nourir, Lesd Mineurs, Luy a donné et donne par cés présentes Une Somme de DEUX MIL livres pour Une fois payer, qu'il Veut et Entend, estre preallablement prise Sur Tous \& chacuns les biens de Sa Succession pour Icelle, Luy demeurer, et Servir de douaire prefix, et en disposer par elle Comme de chose a Elle appartenant, de Vray et Loyal aequest,., ITEM, Led Sieur. Testateur, donne et legue a L'œuvre et fabrique. de la parroisse Matrice de Cette Isle, La somme de Trois Cens livres, qu'il Veut estre payée, par l'executeur de Son présent Testament cy apres Nommé aux Sieurs Marguilliers de lad ${ }^{\text {te }}$. parroisse, apres Son decedz, pour faire prier Dieu pour Le Repos de Son ame, Selon l'ordre qu'il Leur en Sera donné par Lad te. damoiselle Primot Son Espouse, Item, donne \& Legue, led testateur, aux pauvres Necessiteux, de Cette 
ISle, Une somme de Cent livres pour Une fois payer, que led testateur, Veut estre payée, apres Son decedz par Sond Executeur de Son present Testament, aux personnes quil Jugera a propos et pour, Lex'cution de Sond present tes[ ta ]ment a nommé Et Esleu, Noble charles le Moyne aussy Escuyer Sr. de longueuil Son fils Aisné. auquel Il prie et ordonne d'accomplir le Contenu aud son present Testament, Iceluy plustost auguementer que diminuer; Comme Estant Sa derniere Volonte et Intention Ce fust fait, passé, aud Montreal en la chambre, ou est a present detenu Malade led Sieur Testateur, [ (déchiré)] Leu \& releu, par moy dit Nottaire, present lesd tesmoings L'an gbiC. quatre Vingt Cinq le trentie'. Jour de Janvier apres Midy es' presences desd Sieurs Jacques Le Ber Marchands Bourgeois dud Montreal et Jacques la Marque aussy Marchand, Tesmoings y demeurans \& Soubz-Signez avec Led Testateur.

$$
\text { C Le Moyne }
$$

Le Ber

\section{J. Lamarque}

Basset

$$
\text { Nore Royal }
$$

COPIE CONFORME à l'original conservé aux Archives judiciaires de Montréal, greffe Bénigne Basset, no 1609.

(Notule: L'inventaire des biens de Monsieur Le Moyne fut dressé par $\mathrm{Me}$ Bénigne Basset, le 27 mars 1685, sous le numéro 1617 de son greffe mais il est amoindri de son intérêt par le fait que mention n'y est pas faite de l'actif et passif monétaires.-F.L.)

$$
\text { (Document fourni par M. Fernand Lefebvre) }
$$

